\title{
The Research of Game between Business Leader's Leadership Style and Staff Innovative Behavior
}

\author{
Xiaoqing $\mathrm{Bi}^{1, \mathrm{a}}$, Liming Zhan ${ }^{2, \mathrm{~b}}$ \\ ${ }^{1}$ School of Tianjin technology university, Tianjin 300384, China \\ ${ }^{2}$ School of Tianjin technology university, Tianjin 300384, China \\ abi_xiaoqing@163.com, b634025795@qq.com
}

Keywords: Transformational leadership, Transactional leadership, Game, Staff innovative behavior

\begin{abstract}
This article is based on pure strategy and mixed strategy of game theory, Study the game between enterprise organization leaders leadership style and employee innovative behavior. The results of the game show that transformational leadership has positive effect on employees' innovation, whereas transactional leadership has negative effect on employees' innovation. Therefore, in such a competitive market conditions, in order to enhance enterprise competitiveness, company leaders should be good at use transformational leadership style, to increase support for employees, improve the organizational innovation mechanism.
\end{abstract}

\section{Introduction}

With the further development of the market economy, the distribution of resources, industry layout and so on gradually become mature, the competition among enterprises is also intensified. In the context of the fierce competition how to get rid of this predicament, to seek the sustainable development of enterprises is an important issue the enterprise faces.

Many practices show that the only way to win of the enterprise is to maintain sustained innovation ${ }^{[1]}$. To promote the change of economic development mode, the only way is to improve the ability of independent innovation, in the fierce international competition to seize the initiative, to achieve a comprehensive and sustainable economic development. Only innovation can make the organization obtain the competitive advantage, the research has proved that the organization of individual innovation is the basis of the team and organizational innovation ${ }^{[2]}$, because in the organization it's the employee's innovative behavior promote the product design, manufacturing and other aspects of the change. Therefore, it is very important for the enterprise to develop the innovation consciousness and innovation ability of enterprise employees. What is employee innovation? The so-called Employee Innovation: This paper uses the definition of Amabile, in the context of the organization, the new and useful ideas, will help organizations improve their products, services, processes and management procedures and etc ${ }^{[3]}$.

Since it is a creative act, there must have the risk of failure, for example: whether a new method is effective, or can it solve the problem; whether its organization supporting it and so on, that is the problem the enterprise should solve. Because this is related to the enthusiasm of the staff innovation. Enterprises should create a favorable environment for the creation of employees in order to solve their worries. There are many factors that affect the innovation behavior of employees, and there are many internal and external factors. Looking back on the past research, we found that the study of the staff innovation has experienced two stages: the first stage is from the staff themselves, study of the employees different characteristics influence innovation ${ }^{[4]}$; the second stage is from the organizational environment of the staff, analyze the impact of external environment on employee innovation ${ }^{[5]}$.

Leaders are considered to be the key factor in promoting organizational innovation and change, because the leader is the original power of introduce of new ideas for the organization, the setting of the development goals and encourage innovation behavior ${ }^{[6]}$. Scott, Bruce (1994) and Tierney (1999) proposed that leadership style is an important factor affecting the innovation of employees. Organizational leadership is indeed have a direct factor impact on the staff. However, the impact of 
different leadership styles on staff is different. Creative employees like to engage in risky, uncertain and challenging work, which requires that the leader is not likely to be conservative, traditional( Shin \& Zhou 2003), it prefer open, transparent, supportive and challenging environment. There are many types of leadership, Burns divided the leadership into two categories by the transformational and transactional On this basis, this paper studies the game between different leadership styles and the employee's innovative behavior. Previous research methods used are like empirical research, statistical analysis method, structural equation model, etc., there is no direct application of the game theory to study the relationship between leadership and employee innovation behavior, so this paper tries to use the game theory to conduct a preliminary study.

\section{Research Review}

The concept of transformational leadership can be traced back to 1970s, then Burns (1978) through the study of political leaders, divide leadership into transformational and transactional leadership for the first time, considered the Classification is two extreme of a continuum. Bass and etc.(1985) give transformational leadership a further definition: Transformational leadership through make employees aware of the importance of the task, to stimulate the high-level needs, establish an atmosphere of mutual trust between each other that encourage subordinates made effort and sacrifice personal interests to achieve organizational goals, then achieve a better performance more than originally expected. ${ }^{[7]}$ YUKL ${ }^{[8]}$ believes that transformational leadership can lead to the change of organization members' attitudes and ideas, make employees focus on the organization's mission, to achieve organizational goals.In this process, employees will feel accepted by the organization, willing to join in the organization's vision of their leaders.

Transformational leaders have their own charm and appeal. Its foundation is to expand the impact of employees' interest and enhance the ability to innovate, make employees accept the intention and mission of the team, in order to encourage employees to go beyond their interests ${ }^{9]}$. Since the advent of the dimensions of transformational leadership, after the gradual evolution, it was divided into 4 dimensions ${ }^{[10]}$ : Leadership Charm; Organization vision; Personalized care; Intellectual stimulation. Bass (1985) ${ }^{[7]}$ believes that transformational leadership is good at setting up a common vision in the organization, paying attention to staff's guide and encourage, this behavior can enhance the employees' initiative, so as to further enhance it's work performance. At the same time, transformational leadership pay much attention on organizational members' emotional state, encourage communication, and support staff have different ideas, is benefit to innovation behavior. Mumford \& Simonton research shows that a environment support for adventure and change, encourage learning is conducive to employee innovation ${ }^{[11]}$.

Transformational leadership as a new style of leadership, emphasizing innovation and change, which made the organization has a strong external adaptability. Employee's knowledge the support from the relationship between themselves and leaders is good to promote the creative output (Scott \& Bruce, 1994).

For transactional leadership, Bass (1985) ${ }^{[7]}$ believes that it is to set goals, and reward employees when they achieve the requirements of the work. The methods are like : contingent reward, exception management. Transactional leadership is based on the view of social transactions, the relationship between leaders and subordinates is a realistic contract behavior. Leaders and subordinates establish a mutually beneficial relationship through communication and achieve common goals under this relationship. With respect to the transformational leadership, transactional leadership focus much more on performance, lack of human care, it is difficult to make subordinates generate enthusiasm and support to the task, also it's power is limited, therefore, it can not inspire creativity. As Lee finds that transactional leadership has a negative effect on the innovation of subordinates. Amabile(1998)、Deci、Koestner and Ryan(1999) believed that transactional leadership can destroy the positive effect of the intrinsic motivation of the employees, and inhibit the innovation of the staff.

In view of the characteristics of two kinds of leadership style, this paper will set transformational leadership for support leadership, and set transactional leadership for nonsupport leadership. 


\section{Problem description and model hypothesis}

In order to seek the enterprise leaders to support the innovation and the interaction between the leader and the staff, this paper establishes a new game model of the innovation game. Enterprises should invest to employee innovation as subsidies. As a party of the game, staffs use of its own technology and knowledge to make innovation, leaders use incentives to encourage employees to innovate, so as to improve the performance of enterprise innovation.According to the game model of efficiency wage, hypothesis in the enterprise, employees of certainty between innovation work and work enthusiasm, that is, how much of innovation is a function of the determination of work enthusiasm, so that leaders can according to how much understand its working condition, innovation requires no additional supervision. In addition, assume that support for transformational leadership, does not support for transactional leadership.

\section{Pure strategy game model}

Assume that staff innovation only affected by its own factors and leader style. Formed in the leader and staff innovation game, leaders and employees are rational economic man, they pursuit of their own effectiveness maximization

As one of the game party leader's action strategy is: support (transformational) or does not support (transactional); The choice of employees is: innovation or not. Hypothesis in the game is the leader's goal is to pursue innovation benefit maximization, the earnings is $\mathrm{R}$, the size of $\mathrm{R}$ is related about product quantity $\mathrm{Q}, \mathrm{R}=\mathrm{R}(\mathrm{Q})$. If employees take the initiative to innovation, the product quantity is Q1, the corresponding enterprise earnings is R1 = R1 (Q1); Staff under the leadership support innovation, corporate earnings is R2 = R2 (Q2); In any case, employees choose not to innovation of enterprise earnings is R3. Because enterprise support innovation will increase the cost, $\mathrm{C}$, in turn, affects short-term gains, namely Q2 > Q1, R2 > R1. But in the long run is conducive to the sustainable development, without innovation, enterprises are bound to decline. Employee wages is W, innovation performance salary is $\mathrm{H}$, without leaders support innovation failure costs i $\mathrm{C} 1$ will have to be borne by himself (assuming $\mathrm{H}<\mathrm{C} 1$ ).

Game payoff matrix between leaders and employees' innovation is as follows:

\begin{tabular}{|c|c|c|c|}
\hline & \multicolumn{2}{|c|}{ Leaders } \\
\hline & & Support(transformational) & Not support(transactional ) \\
\hline \multirow[t]{2}{*}{ Staff } & innovation & $\mathrm{W}+\mathrm{H}, \mathrm{R}-\mathrm{C}$ & $\mathrm{W}+\mathrm{H}-\mathrm{C} 1, \mathrm{R} 1$ \\
\hline & Not innovation & W,R3-C & W,R3 \\
\hline
\end{tabular}

The game shows that:

1) When leaders use transactional leadership style, employee optimal strategy is not innovation.

2) If leadership style is the transformational leadership, employee's optimal strategy is innovation.

\section{Model evaluation and countermeasures}

After the game model analysis, we can conclude that the innovation of the staff behavior is closely related to the enterprise leadership, and the support of business leaders effected employees' innovative behavior directly ,also the enterprise innovation performance level.

Now enterprises faces fierce competition, how to solve the low competitiveness of current situation of enterprise competition, we can begin from the following points to make this phenomenon.

1) Reduce innovation cost. As a company's leader, should have a full understanding of employees, reduce the cost of organization communication. According to the characteristics of different staff, targeted division of labor, doing things, to play their own advantages, reduce the resistance of the independent innovation. To create a relaxed and free environment for organization staff, give appropriate encouragement to the innovation behavior of employees. Staff's innovation behavior to give appropriate encourage, aiming at the failure of the innovation, not too much, should be timely guidance, provide employees with sufficient capital support, reduce the cost of its innovation.

2) Improve the organization innovation. Organization have to establish a mechanism of innovation's operation, turn the staff's innovation achievements into practical productive forces, in 
order to improve the overall competitiveness of enterprises. Connect the treatment and organizational performance, improve the staff's work enthusiasm.

3) In the process of adapt to the change of environment, leaders need to consider how to improve the organization innovation motivation, to contribute their strength in the organization development. This research shows that: first, the leader can use different leadership behavior affect employee innovative behavior. Specifically, transformational leadership has a positive prediction function on employee innovative behavior, whereas transactional leadership in a certain extent, is not conducive to employees' innovation. To be badly in need of innovation of enterprise, therefore, a leader must be good at use transformational leadership to motivate staff innovation. To work with the guidance of the staff training, and encourage different views and opinions, conducive to innovation of enterprise culture and working atmosphere.

4) Construction of enterprise innovation culture, out of the game trouble. Corporate culture plays an significant role in enterprise development, the formation of an open, scientific, and innovation of enterprise culture is the direction of modern enterprises.

5) Pay attention on the construction of enterprise innovation culture, heip the company out of the game. Enterprise culture is formed in the process of enterprise development, for all the members abide by the code of conduct and value concept, is the soul of the enterprise, the side also reflects the enterprise's guiding ideology, management style, etc. Corporate culture plays an significant role in enterprise development, the formation of an open, scientific, and innovation of enterprise culture is the direction of modern enterprises.

\section{Research limitations and prospects}

There are many factors that can affect employee innovation, in addition to the influence factors of employee's, there are a lot of external factors which has a direct influence on employees. In order to make this paper easy to study, we only consider the enterprise leader leadership's impact on employee innovative behavior. There are many present study which is study the relationship between leadership style and employee innovative behavior, but the game theory method is little used, also the paper we can refer to is less, so this article choose a relatively simple game theory, and research is also relatively simple. In future research may consider evolutionary game approach, will make study more close to reality, make the results more meaningful; in addition, leadership style can be divided into dimension in the future research, study the dimensions of the specific effects of employees' innovative behavior. This paper only analyzes the typical way of transformational and transactional leadership influence on employees' innovation, because the classification of leadership style is varied, in the future stuy can consider other types of leadership style which is affect employees' innovation.

\section{References}

[1] Devanna, M.A.,\& Tichy, N. Creating the Competitive Organization of the 21st Century:The Boundaryless Corporation [J]. Human Resource Mangement, 1990.29: p.445

[2] King, N. Modeling the Innovation Process: An Empirical Comparison of Approaches. Journal of Occupational and Organizational Psychology, 1992, 65: 89-100.

[3] Amabile T. M.A Model of Creativity and Innovation in Organizations[J].Research in Organizational Behavior. 1988,(10):123-167

[4] Barron, F.,\& Harrington, D.M.(1981). Creativity, intelligence, and personality. Annual Review of Psychology, 32, 439-476

[5] Shalley, C., \& Gilson, L. (2004). What leaders need to know: A review of social and contextual factors that can foster or hinder creativity. Leadership Quarterly, 15,33-53.

[6] Mumford M.D., Dansereau F.J. Followers, Motivations, and Levels of Analysis: The Case of Individualized Leadership[J]. Leadership Quarterly,2000,11(3):313-340 
[7] Bass B M. Leadership and Performance: Beyond Expectations[M]. New York: Free Press, 1985

[8]YUKL G. Leadership in Organization[M].2nd ed. Englewood Cliffs: Prentice Hall,1989

[9] Bass B M.Handbook of Leadership [M]. 3rd ed.New York: Free Press,1990

[10] Piccolo R F,Colquitt J A.Transformational Leadership and Job Behaviors:The Mediating Role of Core Job Characteristics[J].Academy of Management Journal,2006,49(2):327-340

[11] Mumford, M. D.,\& Simonton, D. K. Creativity in the work Place :People, Problem, and structures· Journal of Creative Behavior, 1997, 31(l), l-6 